\title{
Improving the Retention and Progression of Learners Through Intelligent Systems for Diagnosing Metacognitive Competencies - A Case Study in UK Further Education
}

\author{
Tej Samani ${ }^{1}$, Ana Isabel Canhoto ${ }^{2}$, Esin Yoruk $^{3}$ \\ 1 Performance Learning and CBiS - Centre for Business in Society, Coventry University, UK; tej@myperformancelearning.com \\ 2 Brunel University London, UK; ana.canhoto@brunel.ac.uk \\ 3 School of Strategy and Leadership and CBiS - Centre for Business in Society, Coventry University, UK; \\ ac1002@coventry.ac.uk
}

\begin{abstract}
Metacognitive competencies related to cognitive tasks have been shown to predict learning outcomes. Less however is known about how metacognitive competencies can enhance the retention and progression of learners in Further Education. This study provides evidence from Performance Learning (PL) and its intelligent system PLEX, PL's proprietary technology, to show how learners' self-reports on meta-cognitive dimensions can be used as predictors of learner retention and progression within the learner's course/s. The results confirm the predictive potential of PLEX technology in early identification of metacognitive competencies in learning and helps learners with developing effective remedies to enhance their retention and progression levels.
\end{abstract}

Keywords: Artificial Intelligence $\cdot$ Meta-Cognition $\cdot$ Machine Learning $\cdot$ Mental Health · Human Interaction · Emerging Technologies · Teaching and Learning

\section{Introduction}

It is estimated that artificial intelligence (AI) has potential to contribute US\$13 trillion to the global economy by 2030 , amounting to $1.2 \%$ additional GDP growth per year [1]. One of the areas that AI opens up new application domains in is the field of education, by radically increasing learner performance and productivity [2]. Current applications of AI in the education sector aim mostly at areas such as teacher effectiveness, and student engagement via tutoring systems [3, 4]. However, the use of AI to identify learners at risk of underperforming, or failing to progress, in their studies is a neglected area of investigation, particularly as far as disadvantaged groups are concerned. Yet, the ability to identify such learners, and intervene in ways that support their academic performance, is of critical importance for the learners themselves [5] and for society $[6,7]$, as well as for the educational institutions where those learners are enrolled [8].

This paper addresses this gap. We analyze the use of AI technology to identify learners at risk of underperforming academically, in order to enable early intervention. Specifically, we consider the PLEX tool, which assesses learners' along 27 psycho- behavioral dimensions that impact on learners' academic performance, and clas- 
sifies them in one of five different levels of academic performance risk. Then, using a case study methodology, we report on the use of this technology at a further education $(\mathrm{FE})^{1}$ college in north of England. Based on data collected from 536 learners at the start and the middle of the academic year, the educational institution developed interventions to support student outcomes and retention, which were cost effective and addressed the needs of specific learners. This resulted in the educational institution identifying $£ 60,000$ in cost savings within two academic terms. Furthermore, the institution decided to embed PLEX in the induction process and extend it to all learners, to support their wellbeing, while achieving additional costs savings. We discuss how other institutions might benefit from the use of AI technology to identify learners at risk of underperforming.

\section{PLEX: An Intelligent Tool to Assess Cognitive and Behavioral Risk}

PLEX is a multiple-choice assessment tool, developed by a UK based venture, Performance Learning Education, based on coaching principles, and which has been applied, refined and validated through application on more than 60,000 learners. The tool assesses learners along 27 psycho-behavioral dimensions which impact on learners' academic performance, by affecting: (i) the process for learning information, (ii) the perception of the institution where they are enrolled, (iii) the perception of their own academic performance, and their own meta cognitive abilities, and (iv) their desired school and professional outcomes. PLEX is distinct from other learning assessment tools in that it considers multiple factors (Table 1), and it also detects the reasons for underperformance.

The "metacognitive domains" items identify the presence of factors that hinder the learners' ability to perform academically. While the absence of these factors does not ensure better class engagement, and does not guarantee academic success, their presence hinders learning [9]. These items are hygiene factors which can prevent or enable academic success. In order to scaffold the learners' academic success, these barriers must be identified and removed. However, removing these barriers will not be enough to guaran- tee academic success. For that end, it is also necessary to improve learners' perceptions [10]. The "perceptions" items assess the learners' attitudes towards various dimensions of learning. While the absence of these items does not impact on learners' ability to learn, it will impact on their drive to learn. The presence of positive perceptions towards specific learning dimensions is critical for academic success. Therefore, the "perceptions" are motivating factors, which driver academic success. Once the scaffolding has been established by removing the metacognition

\footnotetext{
${ }^{1}$ Further education colleges are educational institutions whose courses focus on job specific skills, and are often designed in collaboration with local employers. Some courses are designed as pathways into university degrees. Further education degrees tend to be more affordable than university degrees, with smaller class sizes.
} 
barriers, the negative perceptions must be identified and addressed, in order to build the walks of the learners' academic success.

PLEX's questions are designed to elicit self-assessment from the learners, which has advantages over assessment by a third party (e.g., teachers) [9]. The answers are used to calculate the overall risk level for each learner, with learners being classified into one of five alert levels, from "no alert" to "severe alert". The higher the alert level, the higher the risk that the learners' emotions and behaviour will impact their classroom engagement and performance, as well as their academic success.

Table 1. Dimensions that contribute to the overall PLEX result

\begin{tabular}{llll}
\hline \multicolumn{2}{c}{ Metacognitive domains } & \multicolumn{1}{c}{ Perceptions } \\
\hline 1. & Sleep \& Tiredness & 1. & Towards Effort \& Determination to Work \\
2. & Retaining \& Recalling Information & 2. & Towards Learning \\
3. & Test Anxiety & 3. & Readiness to Learn \\
4. & Focus \& Motivation & 4. & Towards Subject Demands \\
5. & Organization \& Time Management & 5. & Towards the Institution \\
6. & Stress \& Strain & 6. & Towards Self \\
7. & Confidence & 7. & Towards Showing Up to Learn \\
& & 8. & Towards Tutors/Lecturers \\
\hline
\end{tabular}

\section{The Case Study}

During the academic year 2019-20, the PLEX assessment tool was used to calculate the ability and readiness to learn of pupils at a medium-sized FE college located in the North of England, and henceforth referred to as The College. The College serves geographical areas which rank among the top 1\% in England for multiple deprivation. 563 learners undertook the PLEX assessment at the start and middle of the academic year. The second assessment took place before the UK government announced lockdown measures to contain the Covid-19 pandemic ${ }^{2}$. All learners in the tested pool had some cause for concern in terms of risk factors related to academic performance and retention (Table 2). Some learners (10.7\% in Assessment 1 and 18.3\% in Assessment 2) displayed behaviors and attitudes that did not, at the moment, prevent them from achieving academic success (e.g., completing their degree). However, they faced barriers that prevented them from achieving a higher-grade range. More worryingly, the majority of the learners were at a moderate or above risk of failing to succeed academically.

\footnotetext{
${ }^{2}$ See http://www.legislation.gov.uk/uksi/2020/350/contents/made/data.htm
} 
Table 2. Overall Alert levels

\begin{tabular}{|c|c|c|c|c|c|c|c|}
\hline & & $\begin{array}{c}\text { No } \\
\text { Alert }\end{array}$ & $\begin{array}{l}\text { Low } \\
\text { Alert }\end{array}$ & $\begin{array}{c}\begin{array}{c}\text { Moderate } \\
\text { Alert }\end{array} \\
\end{array}$ & $\begin{array}{l}\text { High } \\
\text { Alert }\end{array}$ & Severe Alert & Total \\
\hline \multirow[t]{2}{*}{ Assessment 1} & $\begin{array}{c}\text { Number of } \\
\text { students }\end{array}$ & $\mathbf{0}$ & 60 & 423 & 79 & 1 & 563 \\
\hline & $\begin{array}{c}\text { Proportion } \\
\text { of students }\end{array}$ & $0.0 \%$ & $10.7 \%$ & $75.1 \%$ & $14.0 \%$ & $0.2 \%$ & $100 \%$ \\
\hline \multirow[t]{2}{*}{ Assessment 2} & $\begin{array}{c}\text { Number of } \\
\text { students }\end{array}$ & $\mathbf{0}$ & 103 & 331 & 123 & 6 & 563 \\
\hline & $\begin{array}{c}\text { Proportion } \\
\text { of students }\end{array}$ & $0.0 \%$ & $18.3 \%$ & $58.8 \%$ & $21.8 \%$ & $1.1 \%$ & $100 \%$ \\
\hline \multirow[t]{2}{*}{ Change } & $\begin{array}{c}\text { Number of } \\
\text { students }\end{array}$ & $\mathbf{0}$ & 43 & -92 & 44 & 5 & \\
\hline & $\begin{array}{l}\text { Proportion } \\
\text { of students }\end{array}$ & $0.0 \%$ & $71.7 \%$ & $-21.7 \%$ & $55.7 \%$ & $500.0 \%$ & \\
\hline
\end{tabular}

In between the two assessment points, there was a decrease in the number of learners in the moderate alert level, and an increase in the Low Alert category. This signals that there was an improvement in the underlying behaviors and attitudes that support academic success for these learners. However, as the academic year progressed, there was also an increase in the number of learners in the high and severe alert levels. The College was facing a heightened risk that their learners would underperform in academic assessment. Moreover, there was also an increased risk that learners would fail to progress in their studies, or even complete their degrees [11].

More than three quarters of the learners displayed problems in terms of the foundational behaviors and ability that scaffold academic success. Table 3 shows that learners were at significant disadvantage at the start of the academic year, as they lacked basic techniques for academic success.

Table 3. Alert levels for Metacognition Domain - Assessment 1

\begin{tabular}{|l|c|c|}
\hline \multicolumn{1}{c}{ Domain } & \multicolumn{2}{c}{ Assessment 1 } \\
\cline { 2 - 3 } & $\begin{array}{c}\text { Number of } \\
\text { students }\end{array}$ & $\begin{array}{c}\text { Proportion } \\
\text { of students }\end{array}$ \\
\hline Sleep \& Tiredness & 528 & $94 \%$ \\
\hline Retaining \& Recalling Information & 436 & $77 \%$ \\
\hline Test Anxiety & 501 & $89 \%$ \\
\hline Focus \& Motivation & 432 & $77 \%$ \\
\hline Organisation \& Time Management & 507 & $90 \%$ \\
\hline Stress \& Strain & 545 & $97 \%$ \\
\hline Confidence & 494 & $88 \%$ \\
\hline
\end{tabular}

In assessment 2, there had been a slight improvement in alert levels for the metacognition domain. As per Table 4, around half of the learners were now reporting high levels of test anxiety and problems with organization and time management skills. While half of the cohort was still struggling on these dimensions, there was a significant improvement for "test anxiety", and for "organization and time management skills", respectively. Unfortunately, progress on other foundational skills such as "Sleep \& tiredness", "Stress \& strain", and "Confidence" was negligible. Moreover, 
the scores for "Retaining \& recalling information" and "Focus \& motivation" show a degradation of the situation in terms of these essential skills for academic success.

Table 4. Alert levels for Metacognition Domain-Assessment 2

\begin{tabular}{|l|c|c|c|c|}
\hline \multirow{2}{*}{ Donsin } & \multicolumn{2}{c|}{ Assessment 2 } & \multicolumn{2}{c|}{ Change } \\
\cline { 2 - 5 } & $\begin{array}{c}\text { Number of } \\
\text { students }\end{array}$ & $\begin{array}{c}\text { Proportion } \\
\text { of sudents }\end{array}$ & $\begin{array}{c}\text { Number of } \\
\text { students }\end{array}$ & $\begin{array}{c}\text { Proportion } \\
\text { of sudents }\end{array}$ \\
\hline Sleep \& Tirectness & 506 & $90 \%$ & -22 & $-4 \%$ \\
\hline Retaining \& Recalling Information & 476 & $\mathbf{8 5 \%}$ & 40 & $7 \%$ \\
\hline Test Anxicty & 274 & $49 \%$ & -227 & $-40 \%$ \\
\hline Focus \& Motivation & 462 & $\mathbf{8 2 \%}$ & 30 & $5 \%$ \\
\hline Organisation \& Time Management & 302 & $54 \%$ & -205 & $-36 \%$ \\
\hline Stress \& Strain & 522 & $93 \%$ & -23 & $-4 \%$ \\
\hline Confidence & 426 & $76 \%$ & -68 & $-12 \%$ \\
\hline
\end{tabular}

In summary, in the period under analysis there was a slight improvement in the overall score for meta-cognitive skills of learners at The College (Figure 1).

Figure 1. Change in alert levels for Meta-Cognitive domains

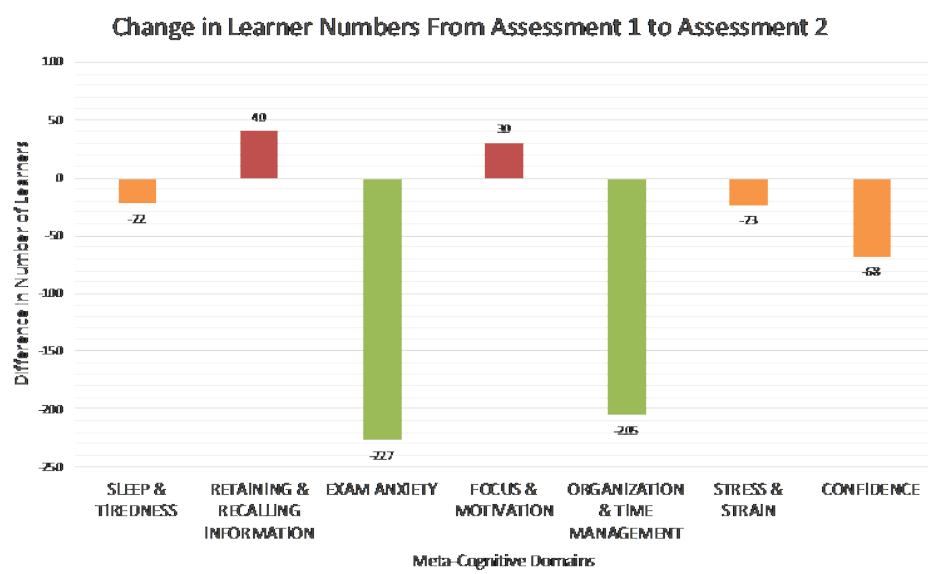

The PLEX results for learners' perceptions show a mixed picture in terms of the motivational factors that drive learning and academic success. In the assessment conducted at the start of the academic year (Table 5), a significant number of learners were in the high-risk category. In particular, the negative attitudes "Towards Subject Demands" and "Towards the Institution", required urgent and moderate attention, respectively. Attitudes for "Readiness to Learn" and "Towards Tutors/ Teachers/ Lecturers" were polarized, with $21 \%$ of learners and $25 \%$ of learners, respectively, requiring urgent attention because they were in the high alert levels. However, $72 \%$ and $57 \%$ would demand only low attention for these two dimensions, as they were deemed to be on the low alert levels. Thus, different groups in The College would require very different interventions. If The College were to adopt a blanket intervention, it would fail to meet the needs of a significant proportion of learners. 
Table 5. Alert levels for Perceptions - Assessment 1

\begin{tabular}{|c|c|c|c|c|c|c|}
\hline & $\begin{array}{c}\text { No } \\
\text { Autetetion }\end{array}$ & $\begin{array}{c}\text { Law } \\
\text { Attention }\end{array}$ & $\begin{array}{l}\text { Moderate } \\
\text { Attenti- }\end{array}$ & $\begin{array}{c}\text { Urgeat } \\
\text { Aftentiva }\end{array}$ & $\begin{array}{l}\text { Fxtremdy } \\
\text { Urgat } \\
\text { Aftenti- }\end{array}$ & $\begin{array}{c}\text { Weingted } \\
\text { risk kend } \\
\text { (1-5) }\end{array}$ \\
\hline & \multicolumn{6}{|c|}{ Assassment 1} \\
\hline Towads Effort \& Detromination To Work & $11 \%$ & $75 \%$ & $7 \%$ & $7 \%$ & $0 \%$ & 2 \\
\hline Towads Leaming & $9 \%$ & $77 \%$ & $T \%$ & $7 \%$ & $0 \%$ & 2 \\
\hline Reafiness To Lean & $0 \%$ & $72 \%$ & $7 \%$ & $21 \%$ & $0 \%$ & 2 \\
\hline Towads Subjert Demands & $0 \%$ & $9 \%$ & $9 \%$ & $82 \%$ & $0 \%$ & 4 \\
\hline Towads The Institution & $8 \%$ & $34 \%$ & $10 \%$ & $47 \%$ & $0 \%$ & 3 \\
\hline Towadls Sedf & $4 \%$ & $75 \%$ & $16 \%$ & $5 \%$ & $0 \%$ & 2 \\
\hline Towadls Showing Up To Leam & $11 \%$ & $75 \%$ & $8 \%$ & $6 \%$ & $0 \%$ & 2 \\
\hline Towadls Tutors' Teachers/ Ledtrers & $11 \%$ & $57 \%$ & $7 \%$ & $25 \%$ & $0 \%$ & 2 \\
\hline Overall percoptioss & $7 x$ & $59 x$ & 97 & $25 x$ & $\theta \mathbf{\theta x}$ & 3 \\
\hline
\end{tabular}

Learners' self-perceptions deteriorated during the academic year (Table 6). In assessment 2 , there was an increase in the proportion of learners requiring urgent interventions across all but two perceptual dimensions. Moreover, there were now $1 \%$ of learners requiring extremely urgent intervention across all perceptual dimensions. As the academic year progressed, many learners developed negative perceptions "Towards Self", "Towards Subject Demands", "Towards Learning", "Towards Effort \& Determination to Work" and "Towards Subject Demands". When learners develop such negative perceptions, they are less likely to challenge themselves, or to try new approaches to problem solving. They may also be less resilient in the face of structural or temporal challenges, such as economic deprivation or a change in employment status. As a result, these learners' academic performance may suffer, and some may even consider abandoning their studies.

Table 6. Alert levels for Perceptions - Assessment 2

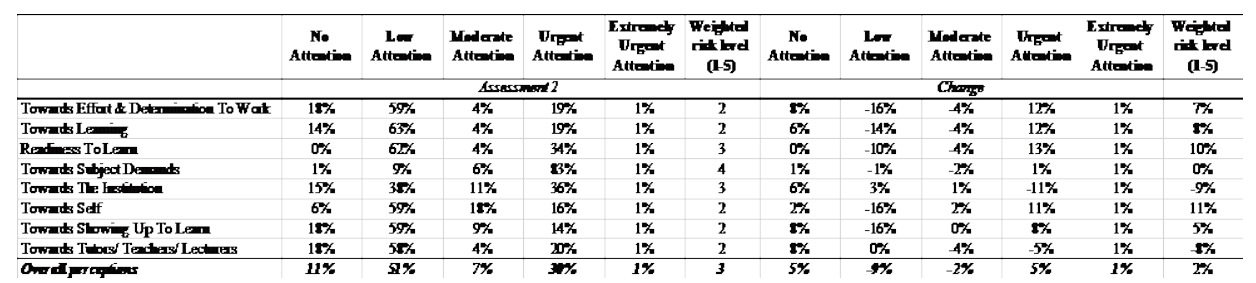

The results for assessment 2 also show an improvement in the "Towards the Institution" and "Towards Tutors/ Teachers/ Lecturers". These indicate an increased appreciation of the institution and of teaching staff. However, overall, there are still significant numbers of learners in the high alert levels $-48 \%$ for the "Towards the Institution" category, and 25\% for the "Towards Tutors/ Teachers/ Lecturers" one. Hence, between one quarter and one half of the learners still require attention in these two categories. The proportion of learners requiring moderate or above levels of attention is even higher for the other perceptions' categories.

In summary, as the academic year progressed, overall learners' self-perceptions deteriorated, indicating a decrease in the drive to learn and, hence, academic success. Moreover, the results showed increased polarization in learners' perceptions. To address this polarization, The College developed and applied targeted measures, reflecting the needs of different groups of learners. 


\section{Discussion and concluding remarks}

The analysis of the metacognition and perception profiles of learners at The College described in the previous sections, provides insight into the causes behind the increase observed in the number of learners in the high and severe alert levels. The PLEX technology shows that this result occurred because a) while there was an improvement in the barriers to learning, the overall level is still very high, meaning that many learners faced metacognition challenges that prevented them from learning; and $b$ ) there was a deterioration in 6 drivers for academic success, meaning that many learners found it difficult to recover from setbacks, and lacked motivation.

The PLEX technology helped The College develop a range of interventions addressing the contextual and personal obstacles faced by the learners. Through the identification of learners in different risk levels, and the nuanced understanding of the causes of underperformance, The College could prioritize their interventions, and target their support, working with learners to overcome the obstacles that they faced. The initiatives developed, based on the PLEX data, resulted in lowered program withdrawals, improved learner outcomes, and increased overall satisfaction. Moreover, The College reported savings of up to $£ 60,000$. The costs were calculated based on the assumed savings associated with the retention of learners deemed at risk, which under normal circumstances have higher instances of early withdrawal or non-completion of Study Programmes. The resulting withdrawals would not only have a significant detriment to the individual learners and their prosperity, but consequently decrease the institutions retention factor and its learner volumes in the lagged funding model. In addition to this, there were also assumed savings factored into the associated costs with delays to identification and triaging of learners wider pastoral support needs.

The role of enabling and motivational factors in supporting learners' academic performance is well understood in the literature. Therefore, many educational institutions adopt some form of program to support their learners' development, over and above the teaching of subject topics and the preparation for exams. However, many educators lack the ability to diagnose the presence of such factors, given the lack of readily available, standardized definitions of metacognition and perceptions, and the interdependency between these dimensions [12]. Moreover, in the absence of historical data connecting metacognition and perceptions on the one hand, and learners' performance on the other, it is not possible for educators to predict the impact of the former on the latter. Consequently, despite the recognized individual, social and organizational costs of academic underperformance, many educating institutions are unable to offer targeted, cost-effective support for their learners, which improves academic outcomes and student retention.

Using AI technology, PLEX offers a standardized tool of diagnosing learners' risk levels, based on their performance across 7 metacognition domains and 8 perceptions, as outlined in this report. This tool, which has been extensively tested and refined over the past decade, enables educational institutions to diagnose problem areas, and to prioritize their interventions (e.g., depending on the type of perception requiring the most urgent intervention). Moreover, the insight obtained via the PLEX assessment supports the development of customized interventions that addresses the specific needs of different leaners (e.g., focused on metacognition domains for some learners, but focused on perceptions for others). The type of proactive, targeted interventions 
enabled by PLEX's data, delivers significant financial benefits for educational institutions, while supporting learners' academic success, and contributing to the local community.

\section{References}

1. Bughin, J., Seong, J., Manyika, J., Chui, M., Joshi, R.: Notes from the AI frontier: modeling the global economic impact of AI. McKinsey Global Institute Report (2018). https://www.mckinsey.com/featured-insights/artificialintelligence/notes-from-the- ai-frontier-modeling-the-impact-of-ai-on-theworld-economy

2. Timms, M.J.: Letting artificial intelligence in education out of the box: educational cobots and smart classrooms. Int. J. Artif. Intell. Educ. 26, 701-712 (2016)

3. Chaudhri, V.K., Lane, H.C., Gunning, D., Roschelle, J.: Applications of artificial intelligence to contemporary and emerging educational challenges. Artif. Intell. Mag. Intell. Learn. Technol.: Part 2, 34(4), 10-12 (2013)

4. McArthur, D., Lewis, M., Bishary, M.: The roles of artificial intelligence in education: current progress and future prospects. J. Educ. Technol. 1(4), 4280 (2005)

5. Kulhánová, I., Hoffmann, R., Judge, K., et al.: Assessing the potential impact of increased participation in higher education on mortality: evidence from 21 European populations. Soc. Sci. Med. 117, 142-149 (2014)

6. UNESCO. Global citizenship education: preparing learners for the challenges of the 21st century. UNESCO (2014). ISBN 978-92-3-100019-5, 978-897094-803-4 (kor). https://une sdoc.unesco.org/ark:/48223/pf0000227729. Accessed 16 Oct 2020

7. Parrett, S.: Recognising the importance of FE in the HE sector. LondonSouth East Colleges (2019). https://www.lsec.ac.uk/news/2239-recognising-fe-inhe. Accessed 16 Oct 2020

8. Beer, C., Lawson, C.: The problem of student attrition in higher education: an alternative perspective. J. Furth. High. Educ. 41(6), 773-784 (2017)

9. Porayska-Pomsta, K.K., Mavrikis, M., Cukurova, M., Margeti, M., Samani, T.: Leveraging non-cognitive student self-reports to predict learning outcomes. In: Penstein Rosé, C., Martínez-Maldonado, R., Hoppe, H.U., Luckin, R., Mavrikis, M., Porayska-Pomsta, K., McLaren, B., Du Boulay, B. (eds.) Artificial Intelligence in Education: 19th International Conference, AIED 2018, London, UK, 27-30 June 2018, Proceedings, Part II, pp. pp. 458-462. Springer, Cham (2018)

10. Bouchey, H. A., Harter, S.: Reflected appraisals, academic self-perceptions, and math/science performance during early adolescence. J. Educ. Psychol. 97(4), 673-686 (2005)

11. Fetler, M.: School dropout rates, academic performance, size, and poverty: correlates of educational reform. Educ. Eval. Policy Anal. 11(2), 109-116 (1989) 
12. Samani, T., Porayska-Pomsta, K., Luckin, R.: Bridging the gap between high and low per- forming pupils through and curricula. In: Andre, E., Baker, R., Hu, X., Rodrigo, M.M.T., du Boulay, B. (eds.) AIED 2017. LNCS (LNAI), vol. 10331, pp. 650-655. Springer, Cham (2017) 